\title{
Chronopharmaceutical Drug Delivery Systems: A Comprehensive Review
}

\author{
Vipin Gupta*, Prashant Kumar \\ *Faculty of Pharmaceutical Sciences, Rama University, Kanpur, Uttar Pradesh, India - 209217. \\ *Corresponding author's E-mail: vipingupta8400@gmail.com
}

Received: 11-05-2021; Revised: 19-07-2021; Accepted: 26-07-2021; Published on: 15-08-2021.

\begin{abstract}
Chronopharmaceutical drug delivery systems release drug at a rhythm that ideally matches the biological requirement of a given disease therapy or prevention. The sound knowledge of the biological processes and their functions utilized in biomedical and pharmaceutical sciences is necessary for effective design and evaluation of pharmaceutical dosage forms. Circadian phase master the circadian clock of the body, the supra chiasmatic nucleus is known to regulate the endogenous circadian rhythms present inside the human body and the peak evidences of some diseases are reported as per circadian rhythm. The secretion of melatonin, a hormone, released by the pineal gland during darkness, help to reset the internal clock, which regulates the timing of different body functions. In certain diseases like asthma, airway resistance increases progressively in early morning, also release of adrenaline and noradrenaline in the morning causes rise in the blood pressure. In hypercholesterolemia, cholesterol synthesis is higher during the night time than day light; in diabetes mellitus blood sugar level is higher in the day time; myocardial insufficiency occurs early in the morning, and many others. The present review addresses the approaches to chronopharmaceuticals, identifies existing technologies, and study of recent chronopharmaceutical drug delivery systems for management of various chronic diseases like diabetes, hypertension and various types of cancers according to the circadian rhythms of diseases in order to optimize therapeutic outcomes and reduce side effects. Recently chronopharmaceutical drug delivery systems are attaining huge importance in the field of pharmaceutical technology for product development because they are proved to reduce dosing frequency, toxicity and also they deliver the drug in particular disease as and when required considering the peak time of the disease, offering better patient compliance.
\end{abstract}

Keywords: Chronopharmaceutics, Product development, Chronotherapeutics, Chronic diseases, Circadian clock.

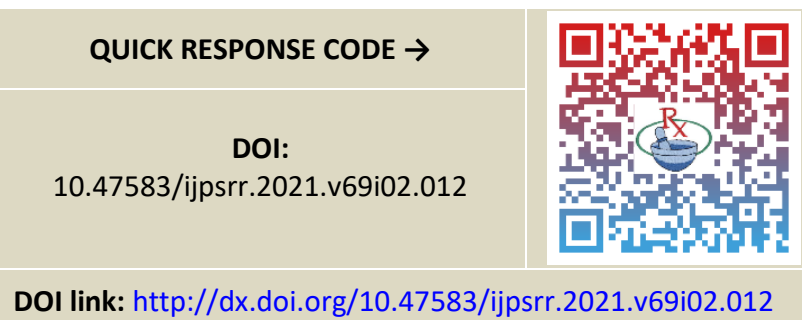

\section{INTRODUCTION}

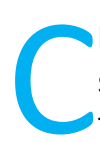

hronopharmaceutics is a class of pharmaceutics (the science and technology of pharmaceutical dosage forms) dealing with the production and development of drug delivery devices that release drug at a rhythm that ideally matches in real time the biological requirement for a given disease therapy or prevention. The terms "chronobiology" and "pharmaceutics" combine to form the term "chronopharmaceutics". ${ }^{1}$ The idea of chronotherapeutics is not new since scientific chronobiology had its origins in 1814 , when Joseph Virey empirically suggested that opium could be dosed late at night rather than early in the morning. Chronobiology is a field of biology that examines timing processes, including cyclic phenomena occurring in living organisms. In other words, it is the study of the circadian rhythms. ${ }^{2}$ The role of the circadian cycle has been recognized many years ago and numerous researches have been conducted in recent years, in the field of chronobiology which were intended to acknowledge the metabolic process of the biological system. ${ }^{3}$ However, the genetic and molecular mechanisms of circadian clocks are still not well understood. ${ }^{4}$ Any dysfunction of the circadian cycle leads to various health problems such as in asthma, airway resistance increases progressively in early morning, also release of adrenaline and nor-adrenaline in the morning causes rise in the blood pressure; in hypercholesterolemia, cholesterol synthesis is higher during the night time than day light; in diabetes mellitus, blood sugar level is higher in the day time; myocardial insufficiency occurs early in the morning and many others. ${ }^{5}$ The pathophysiology of these diseases can be controlled by the circadian rhythm. The safety and efficacy of the drug is achieved by coordinating the peak plasma concentration of the drug with circadian rhythm of the body ${ }^{6,7}$ Circadian phase master the circadian clock of the body, the supra chiasmatic nucleus regulates the endogenous circadian rhythms or bio rhythms present inside the human body. These bio rhythms are regulated by sun light. The light perceived by the visual pathways and the secretion of melatonin, a hormone released by the pineal gland during darkness, help to reset the internal clock that regulates the timing of different body functions. ${ }^{8}$

The chronopharmaceutical drug delivery approach faces major hurdles for the concept of hype to real transition in future clinical practice. With the increase in drug resistance and decreased efficacy of modern drugs, clearly, there is a critical need for novel chronopharmaceutical drug 
products at least in cases such as asthma, cancer and heart diseases either for therapy or prevention. ${ }^{9,10,11}$

Focusing on the current status of drug delivery system, this review highlights the importance of chronopharmaceutical drug delivery system (ChrDDS) with greater emphasis on the recently developed advancements.

The novel chronopharmaceutical drug dosage forms should be safe, effective, easy to use, robust (predictable drug release rate in biological systems) and clinically justified, biocompatible, must have availability of a different triggering biomarker to every disease, must have the feedback control, ease of administration by patients in order to enhance compliance to dosage regimen, and shouldbenon-toxic. ${ }^{12-14}$

Table 1: Application of ChrDDS in management of some diseases/disorders

\begin{tabular}{|c|c|c|}
\hline Disease & Chronological behavior & Drugs used \\
\hline $\begin{array}{l}\text { Duodenal } \\
\text { ulcer }\end{array}$ & $\begin{array}{l}\text { Acid secretion is high in } \\
\text { the afternoon and at } \\
\text { night. }\end{array}$ & H2blockers \\
\hline Cancer & $\begin{array}{l}\text { The blood flow to tumors } \\
\text { is } 3 \text {-fold greater during } \\
\text { each daily activity phase } \\
\text { of the circadian cycle than } \\
\text { during the daily rest phase }\end{array}$ & $\begin{array}{l}\text { Vinca alkaloids, } \\
\text { Taxanes }\end{array}$ \\
\hline $\begin{array}{l}\text { Neurological } \\
\text { disorders }\end{array}$ & $\begin{array}{l}\text { The central path } \\
\text { physiology of epilepsy and } \\
\text { the behavioral } \\
\text { classification of } \\
\text { convulsive events }\end{array}$ & $\begin{array}{l}\text { MAO-B } \\
\text { inhibitor }\end{array}$ \\
\hline Asthma & $\begin{array}{l}\text { the early hours of the } \\
\text { morning, at around } 4 \text { am. } \\
\text { Sudden death in asthma } \\
\text { also tends to occur at this } \\
\text { time }^{56}\end{array}$ & $\begin{array}{l}\text { Anti cholinergic } \\
\text { agents }\end{array}$ \\
\hline Diabetes & $\begin{array}{l}\text { blood glucose levels vary } \\
\text { with the time of day. } \\
\text { Increase the blood sugar } \\
\text { level after meal }\end{array}$ & $\begin{array}{l}\text { Oral } \\
\text { hypoglycemic }\end{array}$ \\
\hline Hypertension & $\begin{array}{l}\mathrm{BP} \text { is at its lowest during } \\
\text { the sleep cycle \& rises } \\
\text { steeply during the early } \\
\text { morning }\end{array}$ & $\begin{array}{l}\text { Nitroglycerine, } \\
\text { calcium channel } \\
\text { blockers, ACE } \\
\text { Inhibitors }\end{array}$ \\
\hline Arthritis & $\begin{array}{l}\text { Pain in the morning \& } \\
\text { more pain in the nigh }\end{array}$ & NSIADS \\
\hline
\end{tabular}

\section{CURRENT SCENARIO OF CHRONOPHARMACEUTICAL DRUG DELIVERY SYSTEM}

\section{In the treatment of cancer}

For better efficacious treatment, patients suffering from cancer often receive maximum tolerated drug dose which may result in toxicity. Cyto-toxicity of chemotherapeutic agents may be reduced by synchronizing the dosing schedule of chemotherapeutic agents to coincide with the circadian rhythm of cells. Several authors reported the influence of circadian dosing time in reducing anti-cancer drug induced toxicity. ${ }^{15}$ Levi et al and Boughatt as et al reported that platinum-based chemotherapy drugs are best tolerated during the nocturnal activity of mice and when administered 12 hours after administration of 5flurouracil, the latter is best tolerated. ${ }^{16}$ In another study, $80 \%$ of the patients suffering from acute lymphoblastic leukemia survived when dosed with 6-mercaptopurine and methotrexate during the evening, whereas $60 \%$ of the patients died when given the same dose and dosage form during the morning. Thus, in order to permit the timevariable delivery of chemotherapeutic agents, chronomodulated pumps have been developed. Incorporation of up to four different drugs can be achieved due to the development of multi-channel programmable-in-time infusion pumps. ${ }^{17}$

Patients with acute lymphoblastic leukaemia, ovarian cancer, endometrial uterine cancer, metastatic colorectal cancer, metastatic transitional cell carcinoma, bladder cancer, progressive metastatic renal cell carcinoma, breast carcinoma, lung carcinoma, hormone-refractory metastatic prostate cancer, and genitourinary tract cancer who received chronotherapy dependent CDDS have always shown good effects. ${ }^{18}$

\section{In the treatment of asthma}

Effect of circadian rhythm can also be seen to reduce the activity of lungs upto $25-50 \%$ in the early morning hours. However this effect is more prominent in asthmatic patients. ${ }^{19}$ During the night hours, airway sensitivity progresses as sensitivity to broncho constrictors such as histamine and acetylcholine increases. ${ }^{20}$ In a survey, Turner-Warwick illustrated that $74 \%$ of the total asthmatic patients included in the study woke up with breathing difficulties. ${ }^{21,22,23}$ In a study it was observed that administration of inhaled corticosteroidonce daily at 15:00 hours was equally effective as four times daily dosing of the same drug. ${ }^{24}$ In another study, it was found that daily single dosing at 17:30 hours was also equivalent to four times dosing. ${ }^{25}$ Thus it can be stated that dosing of inhaled corticosteroid between 15:00 and 17:30 hours could prove to exhibit optimum effect. These findings highlight the importance of dosing medication in synchrony with the circadian rhythms of the body. ${ }^{26,27}$ Chronopharmaceutical of a controlled-release theophylline preparation had been developed to deliver maximum drug concentration in blood at 10-12 hours after dosage. ${ }^{31}$

\section{In the treatment of hypertension}

Several vital functions of the cardiovascular system such as the heart rate, cardiac output, blood flow, platelet aggregability, stroke volume and fibrinolytic activity follow circadian rhythm. ${ }^{32-34}$ Studies revealed that the blood pressure and heart rate in both normotensive and hypertensive patients are comparatively higher during the morning hours upto noon (6:00-12:00 hours) than any other time of the day due to increased sympathetic stimulation i.e. increased release of adrenaline and 
noradrenaline occurs in the morning. ${ }^{35-38}$ At night, when the individual is asleep, decrease in sympathetic outputoccursupto $10-20 \%$ as reported by Ghergel et al. ${ }^{39}$ These factors contributes to an increased risk of cardiovascular diseases such as myocardial infarctions, strokes and angina during the morning hours. ${ }^{40}$ In a study, Douglas summarized that higher risk of stroke occurs upto $49 \%$, increased risk of a heart attack occurs upto $40 \%$ and risk of cardiac death can rise upto $29 \%$ in a group of patients with heart ailments. ${ }^{41}$ Also symptoms of congestive heart failure and vasospasms in Prinzmetal angina are common during sleep.Many antihypertensive drugs when used once daily in the morning, do not regulate blood pressure upto next day early morning. This information can be utilized for the development of chronotherapeutic drug delivery systems in the management of various diseases. ${ }^{42,43} \mathrm{~A}$ prospective study named as the "MAPEC study" was designed specifically to evaluate the hypothesis that chronotherapy at bedtime with 1 or more hypertension medications exerts controlled blood pressure and reduced risk of cardiovascular diseasesas compared to the conventional therapy (all medications ingested in the morning). ${ }^{44}$

\section{In the treatment of peptic ulcer}

The functioning of the gastrointestinal tract is also subjected to circadian rhythm assecretion of gastric acid is the highest during the night while gastric and intestinal motility and gastric emptying are all found to be slower at night.A previous study conducted by Goo et al revealed that GIT emptying rates for consumption of meals at 20:00 hours was on average $50 \%$ slower than the same meal consumed at 08:00 hours. These results could be directly correlated to the pharmacokinetics of orally administered drugs as the disintegration, dissolution and absorption of the drug may be slower at night due to increased gastric acid secretion. ${ }^{45-47}$ The suppression of this increased secretion of gastric acid is an important factor to overcome ulcers or GIT problems. Therefore, for active duodenal ulcer, once daily at bedtime is the recommended dosage regimen for $\mathrm{H}_{2}$ antagonists. A dosage regimen of bedtime $\mathrm{H}_{2}$-receptor antagonists clubbed with chronotherapy has found to cause a profound decrease of 24-hour intragastric acidity withlesser probability of enteric infection and infestation and decreased over growth of potential bacterial with possible formation of $\mathrm{N}$-nitrosamine. ${ }^{48}$

\section{In the treatment of osteoarthritis}

Circadian rhythm is also associated with the diseases related to the skeletal system dysfunctioning. Patients suffering from osteoarthritis are more likely to experience pain symptoms in the morning than at night, while patients with rheumatoid arthritis report having more pain in the morning when compared to the rest of the day. The debilitating symptoms depends on the concentration ofinterleukin- 6 and C-reactive protein which are also subjected to a circadianrhythm. ${ }^{49,50}$
Researchers have reported that a large dose of nonsteroidal anti-inflammatory drug taken twice daily is more effective than four smaller doses, provided that one of the doses is taken at night. ${ }^{20}$ This could be effectively managed by medications based on chronotherapeutics. Rajyalakshmi et al developed a colon specific drug delivery formulation of tramadol hydrochloride for the treatment of arthritis approaching the chronotherapeutic delivery system. Taking long-acting NSAIDs like flubiprofen, ketoprofen and indomethacin once-a-day forms optimizes their therapeutic effect and minimizes or averts their side effects. ${ }^{51,52}$

Table 2: Chronobiological Resources on the World Wide Web

Web Site
http://www.hhmi.org/grants/lectures
http://www.med.stanford.edu/school/
http://www.sleepquest.com/
http://www.srbr.org/
http://www.cbt.virginia.edu/
CLASSIFICATION OF CHRONOPHARMACEUTICAL DRUG
DELIVERY SYSTEMS

\section{The ChrDDS are widely classified in three major categories as follows:}

1. Controlled drug delivery: The first issue of the Journal of Controlled Release (JCR) was published in 1984 Controlled drug delivery systems can include the maintenance of drug levels within a desired range, the need for fewer administrations ${ }^{53}$ The United States Pharmacopoeia (USP) defines the modified-release (MR) dosage form as the one for which the drug release characteristics of time course and/or location are chosen to accomplish therapeutic or convenience objectives not offered by conventional dosage forms.

\section{Evaluation of CDDS (1950-2040)}

$\mathbf{1}^{\text {st }}$ Generation evolution of CDDS 1950 to1980:In this period researchers mainly focused on the mainly three types of routes-

- Oral delivery

- Transdermal delivery

- Drug release mechanisms(Diffusion, osmosis, and ion-exchange)

$2^{\text {nd }}$ Generation evolution of CDDS 1980 to 2010: In this period researchers mainly focused on the mainly Zero Order Release. Eg. Smart polymers\& hydrogels (environment- sensitive, Self- regulated release) Pepide\&Protein delivery (biodegradable depot) Nanoparticles (tumor- targeted delivery, Gene delivery) 
$3^{\text {rd }}$ Generation evaluation of CDDS2010 to 2021: In this period researchers mainly focused on the mainly In vitro vivo correlation prediction of $\mathrm{pK}$ profiles form in vitro release study. eg on- off insulin release (glucose- sensitive release) targeted delivery (anticancer drug, siRNA) ${ }^{54}$

\begin{tabular}{|c|c|c|}
\hline Dutimelan $^{\circledR}$ & Prednisolone & Controlled-release \\
\hline ZocorR & Simvastatin & $\begin{array}{l}\text { Physico-chemical } \\
\text { modification of API }\end{array}$ \\
\hline Moxatag tablet & Amoxicillin & $\begin{array}{l}\text { Extended release } \\
\text { tablets }\end{array}$ \\
\hline $\begin{array}{l}\text { InnoPran XL } \\
\text { extended } \\
\text { release capsules }\end{array}$ & $\begin{array}{l}\text { Propranolol } \\
\mathrm{HCl}\end{array}$ & $\begin{array}{l}\text { Extended } \\
\text { capsules }\end{array}$ \\
\hline InvegaTM & Paliperidone & $\begin{array}{l}\text { Physico-chemical } \\
\text { modification of API }\end{array}$ \\
\hline Theirform & $\begin{array}{l}\text { Diclofenac } \\
\text { sodium }\end{array}$ & Controlled-release \\
\hline Lupron ${ }^{\circledR}$ & $\begin{array}{l}\text { luprolide } \\
\text { acetate }\end{array}$ & Suspension \\
\hline
\end{tabular}

Table 4: List of patents in chronotherapy

\begin{tabular}{|c|c|c|c|}
\hline $\begin{array}{l}\text { S. } \\
\text { No. }\end{array}$ & $\begin{array}{l}\text { Name of the } \\
\text { patent }\end{array}$ & $\begin{array}{l}\text { Patent } \\
\text { Number }\end{array}$ & Assignee/Inventor \\
\hline 01 & $\begin{array}{l}\text { Self-powder } \\
\text { medication } \\
\text { system }\end{array}$ & US3692027 & Everett $\mathrm{H}$ Ellinwood Jr \\
\hline 02 & $\begin{array}{l}\text { Implantable } \\
\text { electro } \\
\text { mechanically } \\
\text { driven device }\end{array}$ & US4003379 & Everett $\mathrm{H}$ Ellinwood Jr \\
\hline 03 & $\begin{array}{l}\text { Pulsatile } \\
\text { technology } \\
\text { beads }\end{array}$ & US4146029 & Everett $\mathrm{H}$ Ellinwood Jr \\
\hline 05 & $\begin{array}{l}\text { Three- } \\
\text { dimensional } \\
\text { printing } \\
\text { technology }\end{array}$ & US5490962 & $\begin{array}{l}\text { Linda G. CimaMichael } \\
\text { J. Cima }\end{array}$ \\
\hline 06 & $\begin{array}{l}\text { Microchip } \\
\text { drug delivery } \\
\text { devices }\end{array}$ & US5797898 & $\begin{array}{l}\text { John T. Santini, } \\
\text { Jr.Michael J. Cima } \\
\text { Robert S. Langer }\end{array}$ \\
\hline 07 & $\begin{array}{l}\text { Pulsatile } \\
\text { technology }\end{array}$ & US6555136 & Kamal K. Midha \\
\hline 08 & $\begin{array}{l}\text { Pulsatile } \\
\text { technology }\end{array}$ & US6635277 & $\begin{array}{l}\text { Vinay K. SharmaJaved } \\
\text { Hussain Habil F. } \\
\text { Khorakiwala }\end{array}$ \\
\hline 09 & Pulsincap ${ }^{R}$ & US6635277 & $\begin{array}{l}\text { Vinay K. SharmaJaved } \\
\text { HussainHabil F. }\end{array}$ \\
\hline 10 & SODAS ${ }^{R}$ & US6066339 & $\begin{array}{l}\text { Paul StarkSean } \\
\text { Cunningham } \\
\text { Jagathesan Moodley }\end{array}$ \\
\hline 11 & DIFFUCAPS & US6066339 & $\begin{array}{l}\text { Paul Stark } \\
\text { Sean Cunningham } \\
\text { Jagathesan Moodley }\end{array}$ \\
\hline
\end{tabular}

2. Time-dependent drug distribution: Time-dependent mechanisms for colon-targeted delivery have been developed using biodegradable polymers that are most often used as excipients in controlled-release systems. the polymers are normally synthetic in nature which dissolve or disintegrate in the gastrointestinal tract without becoming absorbed or degraded significantly.

\section{Pulsatile drug delivery}

Pulsatile drug delivery is may depend on the time or dose, in this systems drug are release as a controlled manger when its necessary pulsatile have been developed to deliver drug effectively to targeting site and releases the drugs when drug is required ${ }^{55}$ The pulsatile drug delivery systems are of have two types -'Single unit system' Multiple unit system.

Profiles of medication release from a pulsatile drug delivery device $a=$ drug release in a "pulse" after a lag time, $\mathrm{b}=$ swift and full drug delivery after a "lag time," and c = steady drug release during a long period of time after a "lag time."

\section{EVALUATIONS/CHARACTERIZATIONS OF ChrDDS}

\section{Drug Content Estimation}

For the determination of drug content the assay of the sample is conducted using UV absorption spectroscopy. The sample is dissolved is suitable solvent and the absorbance is noted for the determination of drug content at specific time

\section{Determination of the time of disintegration}

The time for complete erosion of the plugs is generally determined with help of DT disintegration testing apparatus.

\section{Routine evaluation}

Tablets -Hardness, friability, Variation

Capsule- Moisture content, size shape

Multi-particulate -Flow rate angle of repose, content uniformity particle size distribution

In-vitro dissolution tests (modified USP type 2 app.) are done to determine lag time in delivery and release profile of dosage form

In-vivo studies are done in animals like rabbit, rat etc Success of dosage form depends on clinical trials done on human volutes

\section{FTIR}

Infra-red spectra matching approach was used for the detection of any possible chemical reaction between the drug and the excipients. 
Stability Studies: Stability studies as per ICH guidelines are carried out for optimized formulation and also includes storage at both normal and exaggerated temperature conditions, with the necessary extrapolations to ensure the product will, over its designed shelf life and its physical properties, chemical composition and even its biological availability may be changed.

Water uptake study: The \% water uptake update was calculated as follow:

\section{$\%$ Water uptake $=[(\mathrm{Wt}-\mathrm{Wo} / \mathrm{Wo})] \times 100$}

Where, Wt: Weight of tablet at time $t$ and Wo: is weight of dry tablet.

Swelling index: The swelling index is determined by using this formula SI= (Wet weight-Dry weight/Dry weight) $\times 100$

Rupture test: The Rupture test on coated tablets was carried out using USP paddle apparatus. Here all other Parameters were same as In-Vitro Dissolution Method. The time at which the outer coating layer starts to rupture is called as lag time. This was determined by rupture test

\section{RECENT ADVANCEMENTS IN CHRONOPHARMACEUTICAL DRUG DELIVERY SYSTEMS:}

The approach to design drug delivery according to CDDS is based on the fact that, drug must be delivered when it is mostly needed

\section{* Three-dimensional printing: Breakthrough} technologies is the methods of 3D printing, they are mostly use in the chronotherapy in such way medical implants and surgical models to prosthetic limbs ${ }^{58}$.

* Control IQ: it is a new technology which will let people with diabetes customize their treatment and automatically adjust their insulin levels. Through an advanced hybrid closed-loop system, Control-IQ's algorithm automatically adjusts insulin in response to predicted glucose levels. The aim is to alleviate the strain on patients and care givers through a system that can better mimic what a healthy pancreas does. It is intended for use with a compatible iCGM (sold separately) and ACE pump to automatically increase, decrease, and suspend delivery of basal insulin based on iCGM readings and predicted glucose values ${ }^{59}$. It can also deliver correction boluses when the glucose value is predicted to exceed a predefined threshold. ControlIQ technology is intended for the management of Type 1 diabetes mellitus in persons six years of age and greater ${ }^{60}$

* Nourished: According to Nourished's Head of Brand, Caitlin Stanley, manufacturing supplements via 3D printing opens up a whole new world of personalization possibilities. Typically, active ingredients that show up in vitamins - like ashwagandha and Vitamin A interfere with each other when combined into the same capsule. However, by printing these ingredients on top of each other, Nourished can fuse them into the same bite-sized supplement.
* Eurand's pulsatile and chrono release System: Eurand's Time regulated pulsatile release device will provide one or more rapid release pulses at preset lag times and particular locations, such as for absorption along the GI tract, when Chronotherapy is needed. These skills can help a medication substance's effectiveness and/or side effects be optimised. Eurand, for example, has developed a circadian rhythm release $(C R R)^{60}$.dosage form for a cardiovascular drug, Propranolol hydrochloride, with a four hour delay in release after oral administration. Administered at bedtime, Propranolol is released after the initial delay such that maximum plasma ${ }^{61}$

* CODAS Technology: Elan Drug Technology developed CODAS $^{\circledR}$ technology to achieve prolonged interval. The many advantages of the CODAS $^{\circledR}$ technology include a delivery profile designed to compliment circadian pattern, controlled onset, an extended release delivery system ${ }^{62}$ rate of release essentially independent of $\mathrm{pH}$, posture and food, "sprinkle" dosing by opening the capsule and sprinkling the contents on food, reduction in effective daily dose and drug exposure, gastrointestinal tract targeting for local effect and reduced systemic exposure to achieve a target profile ${ }^{63}$

* PRODAS $^{\circledR}$ technology can be used to pre-program the release rate of a drug. It is possible to incorporate many different mini tablets, each one formulated individually and programmed to release drug at different sites within the gastro-intestinal tract. It is also possible to incorporate mini tablets of different sizes so that high drug loading is possible by incorporating PRODAS Technology ${ }^{64}$

* TIMERx technology it is a controlled release tablet formulation forms a hydrophilic matrix in the aqueous media and controls the drug release for 24 hours. It is a cost-effective technology 65

* Gel-CapTM technology: Gel-Cap TM technology is based on highly viscous material called sucrose acetate isobutyrate (SAIB), which is insoluble in water, but soluble in alcohol. Formulations prepared with SAIB are difficult to crush, break, freeze and snort due to its high viscosity. In addition, because it is insoluble in water, extraction of drug out of the dosage form is difficult. After oral administration of the Gel-CapTM formulation, the gelatin capsule and solvents dissolve, and the drug is released in a controlled manner from the adhesive SAIB matrix ${ }^{65-66}$

* In situ forming devices: This technology is also known as "AtrigelTM Technology" since it was developed by Atrix Laboratories in the 1980 In 1989, Lupron ${ }^{\circledR}$ Depot, monthly intramuscular injection of luprolide acetate, was approved by the FDA. Luprolide acetate is a luteinizing hormone-releasing hormone (LHRH) agonist, which reduces the testosterone production and treats prostate cancer ${ }^{67}$ 
* ACCU-BREAK Technology The Accu-T technology allows for five layers in a taller-than-wide tablet, and the incorporation of drug-free layers to serve one of two purposes hysical barrier between active ingredients. This barrier allows the formulation of incompatible actives with no worries about co-mixing and resultant physical or chemical stability issues. The technology utilises machinery that can produce tablets with up to five compressed layers so the use of more than one drug-free layer can facilitate a "poly pill" wth three different API-containing formulations separated by inert/placebo layers

\section{Limitation of ChrDDS}

- Patients who work shifts (alternating day and night) can find chronotherapy to be too difficult.

- Gastrointestinal transit times vary not only from patient to patient but also within patients as a result of food intake, stress. and illness, thus a single-unit pulsed release system may give higher variability compared to a multiple unit system.

- For multiple unit systems, drug layering or core making is a time-consuming and difficult-to-optimize operation. major drawbacks of existing oral chronotropic systems are their dependence humm action to trigger the drug release.

\section{CONCLUSION}

In present scenario chronopharmaceutical drug delivery systems are proved to effectively treat various chronic diseases like arthritis, asthma, hypertension and various cancers. It is well known that the peak and patho physiology of the disease is modulated by the circadian rhythm as well as biological clock. Circadian rhythm of the body is an important concept for understanding the optimum need of drug in the body. Diseases have certain circadian rhythms and hence the timing of medication regimens is very significant in treating chronic conditions. Hence the development of the chronopharmaceutical drug delivery systems to release the drug according to the biological clock. The chronotherapeutic systems are developed and commercialized for the delivery of proteins, hormones, pain medications and other pharmaceutical compounds. The systems are biocompatible and reduced dosing frequency with better patient compliance.

\section{REFERENCES}

1. Chopra et al. / Chronotropic Systems; an Emerging Trend in Drug Delivery. IJPCR January-March, 2010;2(1):10-19.

2. Arendt J. Biological rhythms: the science of chronobiology. J R Coll Physicians Lond. 1998 Jan-Feb;32(1):27-35.

3. Lack LC, Wright HR. Chronobiology of sleep in humans. Cell Mol Life Sci. 2007 May;64(10):1205-15.

4. HülyaÇakmur (April 2nd 2018). Circadian Rhythm and Chronobiology, Circadian Rhythm - Cellular and Molecular Mechanisms, Mohamed Ahmed El-Esawi, IntechOpen, DOI: 10.5772/intechopen.75928. Available from: https://www.intechopen.com/books/circadian-rhythmcellular-and-molecular-mechanisms/circadian-rhythmand-chronobiology.

5. Vineela P., Overview on Chronopharmaceutical Drug Delivery System. American Journal of PharmTech Research 2014.

6. Kikuchi A, Okano T. Pulsatile drug release control using hydrogels. Adv Drug Deliv Rev 2002;54: 53-77

7. ASCHOFF, J. Exogenous and endogenous components in circadian rhythms. Cold Spring Harbor Symposia on Quantitative Biology: Volume XXV.

8. Philip AK, Philip B. Chronopharmaceuticals: hype or future of pharmaceutics. Curr Pharm Des. 2011;17(15):1512-6.

9. D.A. Oren, T.A. Wehr, Hypernyctohemeral syndrome after chronotherapy for delayed sleep phase syndrome, $\mathrm{N}$ Engl J. Med. 1992;327:1762.

10. B.B. Youan, Chronopharmaceutics: gimmick or clinically relevant approach to drug delivery, J. Control. Release 2004;98:337-353.

11. Bi-Botti C. Youan. Chronopharmaceutical drug delivery systems: Hurdles, hype or hope? Advanced Drug Delivery Reviews 2010;62: 898-903.

12. Maurya K.K, Semwal B.C., Chronopharmacology: A tool for therapy of diseases. International research journal of pharmacy 2012;3-5.

13. M.Menaker,Circadianrhythms.Circadianphotoreception,Sc ience,2003;294:2511-2515.

14. BottiC.Youan,Chronopharmaceutics:gimmickorclinicallyrel evantapproachtodrugdelivery?,journalofcontrolledreleas, 2004;98: 337-353.

15. Ravichandiran V, Suba V, Umadevi S. K, Jayavasavi G, Kausalya J, Saraswathy T. Chrono pharmaceutical drug delivery system. Biomed Pharmacol J 2009;2(2),56-60.

16. Lévi F, Focan C, Karaboué; A, de la Valette V, Focan-Henrard D, Baron B, Kreutz F, Giacchetti S. Implications of circadian clocks for the rhythmic delivery of cancer therapeutics. Adv Drug Deliv Rev. 2007;59:1015-1035.

17. Boughattas $N$, Lévi $F$, Fournier $C$, Lemaigre $G$, Roulon $A$, Hecquet $B$, Mathé; $G$, Reinberg $A$. Circadian rhythms in toxicities and tissues uptake of oxaliplatin in mice. Cancer Res. 1989;49:3362-3368.

18. Baker, Danial E. PharmD, Application of Chronotherapy to the Treatment of Cancer: Can Changing the Timing of Drug Administration Influence Efficacy and Toxicity July 2004;2(3):41-46.

19. Lemmer B. The clinical relevance of chronopharmacology in therapeutics. Pharmacol Res. 1996;33:107-115.

20. Kraft M, Martin RJ. Chronobiology and chronotherapy in medicine. Disease-a-month. 1995;41;506-575.

21. Burkioka N, Sako T, Tamita K, Miyota M, Suyama H, Igish T, Shimizu E. Theophylline chronotherapy of nocturnal asthma using bathyphase of circadian rhythm in peak expiratory flow rate. Biomed Pharmacother. 2002;55:142146 
22. Sutherland ER. Nocturnal asthma. J Allergy ClinImmunol. 2005;116:1179-1186.

23. Turner-Warwick M. Epidemiology of nocturnal asthma. Am J Med. 1988;85:6-8.

24. Mastiholimath VS, Dandagi PM, Jain SS, Gadad AP, Kulkarni AR. Time and $\mathrm{pH}$ dependent colon specific, pulsatile delivery of theophylline for nocturnal asthma. Int J Pharm. 2007;328:49-56.

25. Gwen SS. Nocturnal asthma: Mechanisms and management. Mount Sinai J Med. 2002;69:140-147.

26. Pincus DJ, Szefler J, Ackerson LM, Martin RJ. 1995 Chronotherapy of asthma with inhaled steroids: The effect of dosage timing on drug efficacy. J Allergy ClinImmunol. 1995;95:1172-1178.

27. Pincus DJ, Humeston TR, Martin RJ. Further studies on the chronotherapy of asthma with inhaled steroids: The effect of dosage on drug efficacy. J Allergy Clinlmmunol. 1997;100:771-774.

28. R.S. Geha, E.O. Meltzer, Desloratadine: a new, nonsedating, oral anti-histamine, J. Allergy Clin. Immunol. 2001;107:751-762.

29. L. Peterson, Trends-in-Medicine, 2002.

30. Hansen-Flaschen, John. "Asthma".Encyclopedia Britannica, 18 Mar. 2021, https://www.britannica.com/science/asthma. Accessed 27 March 2021.

31. Burioka N, Sasaki T. [Chronopharmacology and chronotherapy for asthma by using PEF]. Nihon Rinsho. 1996 Nov;54(11):2956-61.

32. Lemmer B. The clinical relevance of chronopharmacology in therapeutics. Pharmacol Res. 1996;33:107-115.

33. Smolensky $\mathrm{MH}$. The emerging role of chronotherapeutics in managing hypertension. Am J Hypertension. 1995;8:7A.

34. Lemmer B. The importance of circadian rhythms on drug response in hypertension and coronary heart disease-from mice to man. PharmacolTherapeut. 2006;111;629-651.

35. Douglas JG. Compliance with antihypertensive therapy: Is it time for chronotherapy? Am J Hypertension. 2002;15:A238.

36. Prisant LM. Chronotherapeutics: A surge of ideas. Clinical Cornerstone. 2004;6:7-17.

37. Smith DHG. Pharmacology of cardiovascular chronotherapeutic agents. Am J Hypertension. 2001;14:296-301.

38. Prisant LM. Hypertension and chronotherapy: Shifting the paradigm. Am J Hypertension. 2001;14:277-279.

39. Gherghel D, Hosking SL, Orgul S. Autonomic nervous system, circadian rhythms, and primary open-angle glaucoma. Survey Ophthalmol. 2004;49:491-508

40. Smith DHG. Pharmacology of cardiovascular chronotherapeutic agents. Am J Hypertension. 2001;14:296-301.

41. Douglas JG. Compliance with antihypertensive therapy: Is it time for chronotherapy? Am J Hypertension. 2002;15:A238.
42. Smolensky MH, Portaluppi F. Chronopharmacology and chronotherapy of cardiovascular medications: Relevance to prevention and treatment of coronary heart disease. Am Heart J. 1999;137:14-24.

43. Gurny, R., Junginger, H.E. and Peppas, N., Eds., In; Pulsatile DrugDelivery: Current Application and Future Trends, WissenscheflicheVerlagsgesellschaft, Stuttgart, Germany, 1993, 36.

44. Hermida RC, Ayala DE, Mojón A, Fernández JR. Influence of circadian time of hypertension treatment on cardiovascular risk: results of the MAPEC study. Chronobiol Int. 2010 Sep;27(8):1629-51.

45. Lemmer B. Implications of chronopharmacokinetics for drug delivery; antiasthmatics, $\mathrm{H} 2$-blockers and cardiovascular active drugs. Adv Drug Deliv Rev. 1990;6:83-100.

46. Youan BBC. Chronopharmaceutics: Gimmick or clinically relevant approach to drug delivery. J Control Rel. 2004;98:337-353

47. Goo RH, Moore JG, Greenberg E. Circadian variation in gastric emptying of meals in man. Gastroenterology. 1987;93:515-518.

48. Humphries TJ, Root JK, Hufnagel K. Successful drugspecificchronotherapy with the $\mathrm{H} 2$ blocker famotidine in the symptomatic relief of gastro-esophageal reflux disease. Ann New York AcadSci 1991; 517-518.

49. Cutolo M, Seriola B, Craviotto C, Pizzorni C, Sulli A. Circadianrhythms in RA. Ann Rheum Dis. 2003;62:593-596.

50. Sher P, Ingavle G, Ponrathnam S, Pawar AP. Low density porouscarrier based conceptual drug delivery system. MicroporousMesoporous Materials. 2007;102:290-298.

51. RajyalakshmiKadiyam and Y. Indira Muzib Colon specific drug delivery of tramadol $\mathrm{HCl}$ for chronotherapeutics of arthritis 2015 Jan-Mar; 5(1): 43-49

52. Lemmer B. Chronopharmacokinetics: implications for drug treatment. J Pharm Pharmacol. 1999 Aug;51(8):887-90.

53. DebjitBhowmik1, Harish GopinathControlled Release Drug Delivery Systems 2012;1(10):12-19.

54. Yun YH, Lee BK, Park K. Controlled Drug Delivery: Historical perspective for the next generation. $J$ Control Release. 2015;219:2-7.

55. Ryo Yoshida a, Kiyotaka Sakai Pulsatile drug delivery systems using hydrogels Advanced Drug Delivery Reviews, 1993;11:85-108.

56. Cochrane GM, Clark TJH. A survey of asthma mortality in patients between ages 35 and 64 in Greater London Hospitals in 1971. Thorax. 1975;30:300-305

57. Bhat et al Int J Pharm Pharm Sci, 2011;3(2):18318.

58. Kovatchev B, Tamborlane WV, Cefalu WT, Cobelli C. The Artificial Pancreas in 2016: A Digital Treatment Ecosystem for Diabetes. Diabetes Care. 2016 Jul;39(7):13-19.

59. M. Filippi, et al. Magnetic nanocomposite hydrogels and static magnetic field stimulate the osteoblastic and vasculogenic profile of adipose-derived cells Biomaterials 2019;223:91-95. 
60. Jain D, Raturi R, Jain V, Bansal P, Singh R. Recent technologies in pulsatile drug delivery systems. Biomatter. 2011;1(1):57-65. doi:10.4161/biom.1.1.17717

61. F Portaluppi, B Lemmer. Chronobiology and chronotherapy of ischemic heart disease. Adv Drug Deliv Rev 2007,59-65

62. Panoz DE. Geoghegan, Edward J, inventors. 1989 Sept. 15/ Controlled absorption pharmaceutical composition, US Patent 4863742.

63. Amin Abbasi, Neda Hajipour, Paniz Hasannezhad, Amir Baghbanzadeh, Leili Aghebati-Maleki. Potential in vivo delivery routes of postbiotics. Critical Reviews in Food Science and Nutrition 2020;22:31-39.
64. Rewar S, Bansal BK, Singh CJ, Sharma AK, Pareek R : pulsatile drug delivery system: an overview 2014;5(2): 1943-1955.

65. Encyclopedia of Controlled Drug Delivery (2 Volumes). E Mathiowitz (Ed.), John Wiley \& Sons, New York, NY, USA ,1999.

66. Webster LR. PTI-821: Sustained-release oxycodone using gel-cap technology. Expert Opin Investig Drugs 2007;66:3439.

67. Sartor O. Eligard: Leuprolide acetate in a novel sustainedrelease delivery system. Urology 2003;61:25-31.

Source of Support: The author(s) received no financial support for the research, authorship, and/or publication of this article.

Conflict of Interest: The author(s) declared no potential conflicts of interest with respect to the research, authorship, and/or publication of this article.

For any question relates to this article, please reach us at: editor@globalresearchonline.net

New manuscripts for publication can be submitted at: submit@globalresearchonline.net and submit_ijpsrr@rediffmail.com 